\title{
Gut reaction
}

A bacterium that causes ulcers and stomach cancer

is on the decline, but not everyone is celebrating. John Whitfield talks to the experts who have misgivings about its impending extinction.

Endangered species: Helicobacter pylori, part of our gut flora, may offer clues to human migration.

S ave the bacterium! It's an unlikely rallying cry, particularly when the microbe in question causes ulcers and stomach cancer. But Helicobacter pylori is in steep decline in many parts of the world, thanks to improved sanitation and the widespread use of antibiotics, and some biologists are beginning to wonder whether its disappearance is really for the best. In the West, the bacterium's demise has been dramatic - half of the US population aged 60 and over are infected with $H$. pylori compared with only $20 \%$ of those under 40 .

Although most gastroenterologists view $H$. pylori's disappearance with satisfaction, other researchers point to hints that the bacterium may help to protect against conditions such as infant diarrhoea and oesophageal disease. Some experts say that removing an important member of our intestinal flora will have unforeseen consequences for our inner ecosystem, and so our health. "We have no good sense of the microbial ecology of humans," says infectiousdisease specialist Julie Parsonnet of Stanford University in California. "H. pylori infection revs up the immune system — what happens to our ability to respond to other infectious agents when that isn't there?" What's more, if H. pylori does disappear, so too will an opportunity to use studies of the bacterium to retrace the evolution and migration of human populations.

The debate over $H$. pylori begins with the question of how it got into us in the first place. Most mammals seem to have their own species of Helicobacter in their stomachs, leading some researchers to suggest

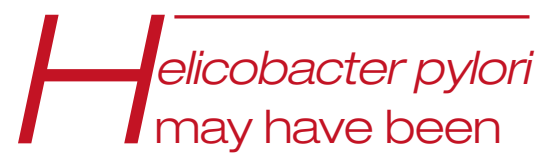

a success because

it offers advantages

to its host.

that the relationship between microbe and host predates the evolution of modern humans. But others think that H. pylori's hook-up with humans, and subsequent spread around the world, was more recent.

That's the view taken by geneticist Douglas Berg of Washington University in St Louis, Missouri. Berg and his colleagues looked at more than 500 strains of the bacterium taken from people in five continents. Native Peruvians had bacteria more similar to Spaniards, they found, even though their genes are more similar to those of East Asians - the group that settled the Americas about 12,000 years ago. This led Berg and his colleagues to suggest that the conquistadors may have carried the bacterium to South America about 500 years ago ${ }^{1}$, and that the continent's first humans arrived with virgin stomachs.

Martin Blaser disagrees. A microbiologist at New York University, he believes that Helicobacter has long been part of the gut flora of all humans. Late last year, Blaser and his colleagues seemed to reaffirm the ancient origins of American H. pylori, when they discovered strains closely related to the East Asian version of the bacterium in native people living in remote regions of Amazonia ${ }^{2}$. And in unpublished work, pathologist Marvin Allison of the Medical College of Virginia in Richmond has detected H. pylori in the stomachs of 1,800-year-old Chilean mummies. In areas where Europeans and Amerindians had mixed, Blaser believes, indigenous strains have fallen victim to microbial imperialism.

Berg considers the case to be unproven. Japanese and Chinese adventurers arrived in the New World about the same time as the Spanish, he points out, and they may have been the source of the Asian H. pylori. "It's still very controversial," he says. "How one interprets the evidence depends on one's biases."

\section{A family affair}

Knowing more about how $H$. pylori spreads would help to solve this puzzle, but so far we have only a rough sketch. Carriers usually pick up the bacterium before the age of ten and stay infected for the rest of their lives. Infected people shed large quantities of H. pylori in their diarrhoea and vomit ${ }^{3}$, which explains the microbe's success in regions with poor hygiene and sanitation. As a result, those at the bottom of the socioeconomic scale and people in poor countries are more likely to be infected. The bug most often spreads vertically, from parents to offspring down the generations; there is very little transmission between adults.

Our tendency to keep $H$. pylori in the family means that bacterial and human histories mirror one another. A less faithful microbe that swapped between the members of a generation, a process called horizontal 
